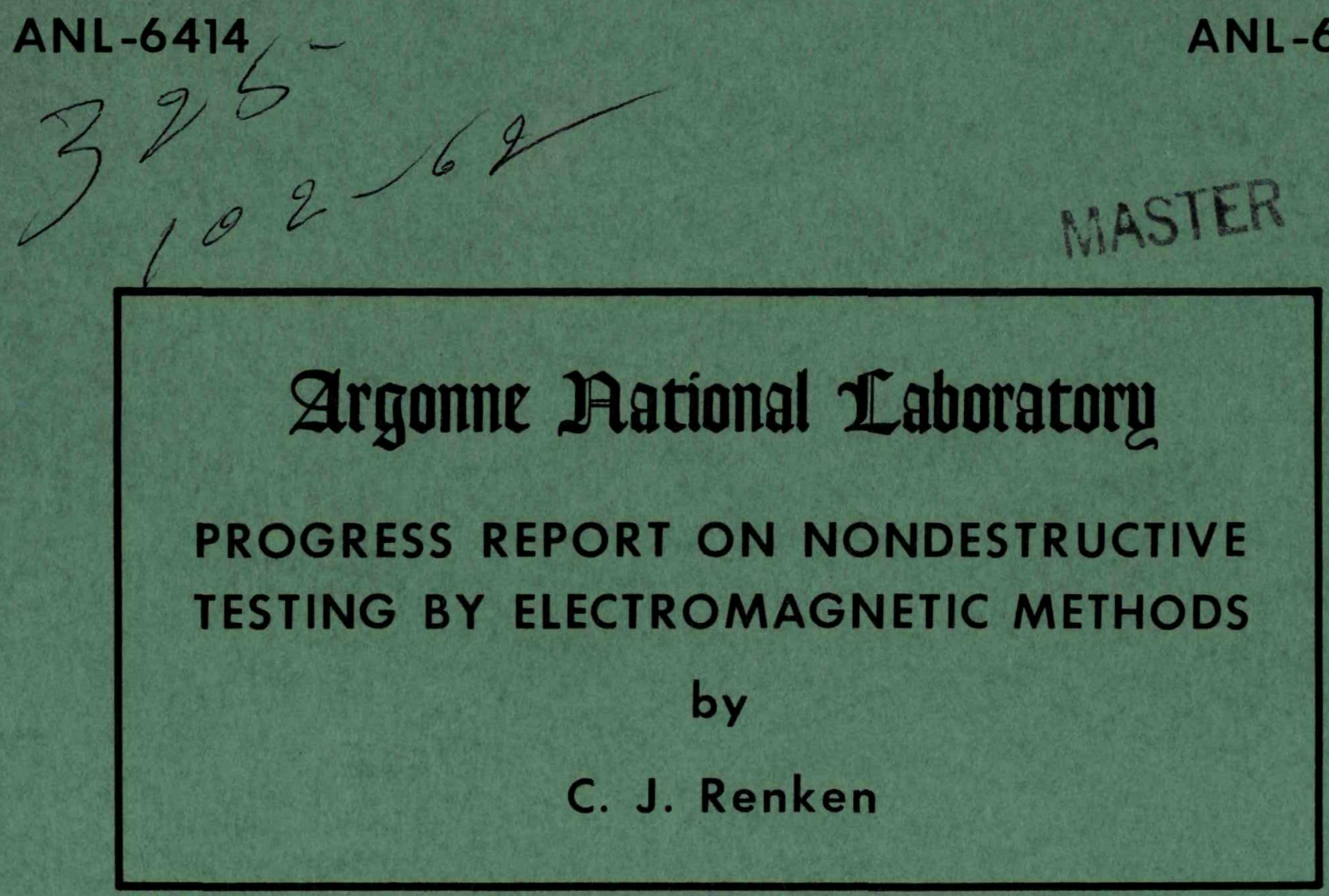




\section{DISCLAIMER}

This report was prepared as an account of work sponsored by an agency of the United States Government. Neither the United States Government nor any agency Thereof, nor any of their employees, makes any warranty, express or implied, or assumes any legal liability or responsibility for the accuracy, completeness, or usefulness of any information, apparatus, product, or process disclosed, or represents that its use would not infringe privately owned rights. Reference herein to any specific commercial product, process, or service by trade name, trademark, manufacturer, or otherwise does not necessarily constitute or imply its endorsement, recommendation, or favoring by the United States Government or any agency thereof. The views and opinions of authors expressed herein do not necessarily state or reflect those of the United States Government or any agency thereof. 


\section{DISCLAIMER}

Portions of this document may be illegible in electronic image products. Images are produced from the best available original document. 


\section{LEGAL NOTICE}

This report was prepared as an account of Government sponsored work. Neither the United States, nor the Commission, nor any person acting on behalf of the Commission:

A. Makes any warranty or representation, expressed or implied, with respect to the accuracy, completeness, or usefulness of the information contained in this report, or that the use of any information, apparatus, method, or process disclosed in this report may not infringe privately owned rights; or

B. Assumes any liabilities with respect to the use of, or for damages resulting from the use of any information, apparatus, method, or process disclosed in this report.

As used in the above, "person acting on behalf of the Commission" includes any employee or contractor of the Commission, or employee of such contractor, to the extent that such employee or contractor of the Commission, or employee of such contractor prepares, disseminates, or provides access to, any information pursuant to his employment or contract with the Commission, or his employment with such contractor.

Price 75 cents. Available from the Office of Technical Services, Department of Commerce, Washington 25, D.C. 
ANL-6414

Instruments

(TID-4500, 17th Ed.)

AEC Research and

Development Report

\section{ARGONNE NATIONAL LABORATORY \\ 9700 South Cass Avenue \\ Argonne, Illinois}

\section{PROGRESS REPOR T ON NONDESTRUCTIVE TESTING BY ELECTROMAGNETIC METHODS \\ by \\ C. J. Renken}

Metallurgy Division

Program 12.1.5

Portions of the material in this report have appeared in the following Metallurgy Division reports:
ANL-6099
Pages 55-56
December 1959
ANL-6330
Pages 66
December 1960
ANL-6330
Pages 130-131
December 1960

July 1962

Operated by The University of Chicago

under

Contract W-31-109-eng-38 


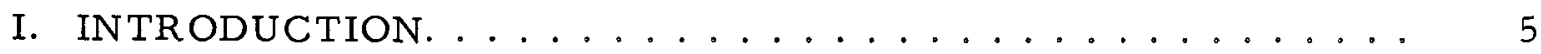

II. A DUAL-FREQUENCY EDDY CURRENT TEST SYSTEM WITH

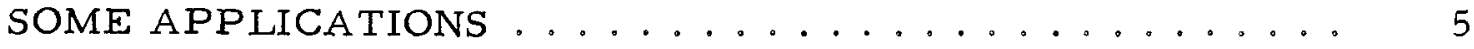

A. Introduction. ................... 8

B. Eddy Current Tests on Tubing for Core IA of the

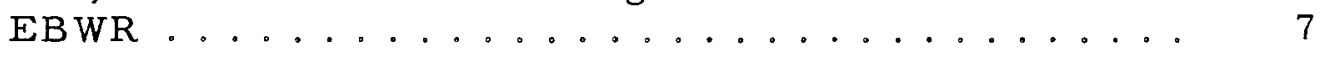

C. The Inspection of the $2 \frac{1}{4} \%$ Croloy Tubing for the

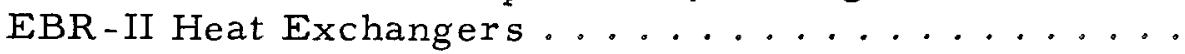

D. Eddy Current Tests on Stainless Steel Tubing for Use in the EBR-II Blanket. ................

E. Tests of Zircaloy-2 Tubing Intended for Use in the EBR-I Mark-IV ..................

F. An Evaluation of the Quality of Zircaloy-2 Tubing of the Type Proposed for Use in the EBWR Core-II ....

III. A THROUGH TRANSMISSION SYSTEM USING PULSED EDDY

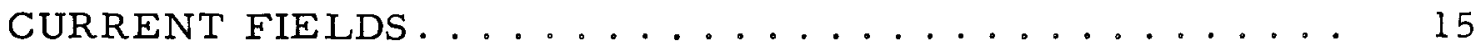

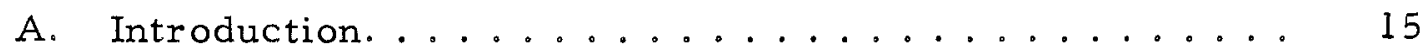

B. Diffusion of Current Fields in Good Conductors..... 15

C. The Use of Pulsed Fields............... 16

D. The Use of Masks to Obtain Improved Resolution..... 17

E. Experimental Data on the Field around the Aperture... I 19

F. Block Diagram................... 20

G. Possible Applications ................. 21

IV. A PULSED-FIELD REFLECTION SYSTEM WHICH USES FIELDS OF SMALL CROSS-SECTIONAL AREA . . . . . . . 22

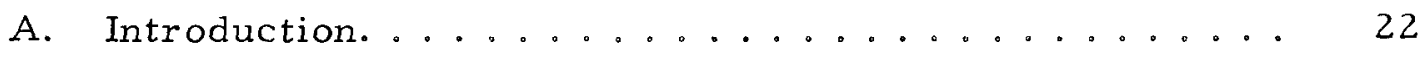

B. The Reflection of Time-varying Electromagnetic Fields from Good Conductors................. 22

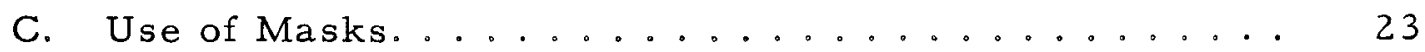

D. The Signal Produced by the Mask-Aperture Assembly。 23

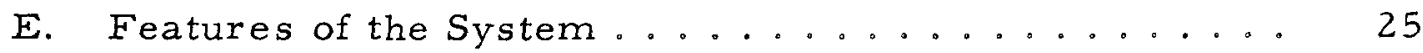

F. Some Advantages of This Approach .......... 26 


\section{LIST OF FIGURES}

No.

Title

Page

1 A Block Diagram of the Dual-frequency Eddy Current

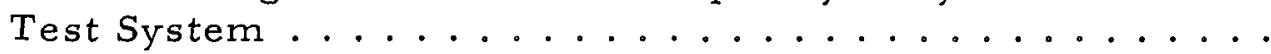

2 A Microphotograph of a Cross Section of the Tube at the Point Marked 105A in Figure 3............ 8

3 Part of the Trace Obtained from the Inspection of Tube \#2644. A Deflection of $\frac{1}{4}$ in. Represents About a

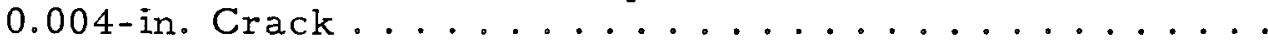

4 A Lap Detected in Croloy Heat Exchanger Tubing by the Eddy Current Test Equipment............... 10

5 Another Lap Detected in Croloy Heat Exchanger Tubing by the Eddy Current Test Equipment .............

6 A Typical Small Radial Crack Often Seen in Small-diameter Thin-wall Zircaloy-2 Tubing .............

7 A Flaw Detected in 0.299-in. Zircaloy-2 Tubing. The tube wall has been nearly completely penetrated. This specimen has been very heavily etched to make the defect more

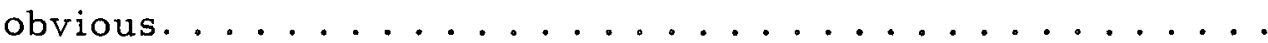

8 Defects Detected by the Eddy Current Test Equipment in 0.420-in.-OD Tubing of the Type Proposed for Use in

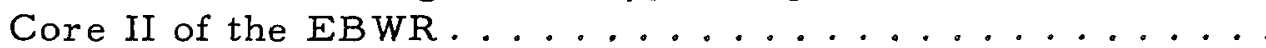

9 Defects Detected by the Eddy Current Test Equipment in 0.420-in.-OD Tubing of the Type Proposed for Use in

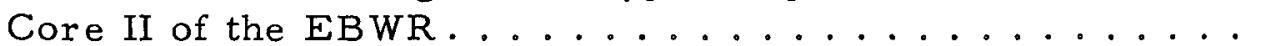

10 Defects Detected by the Eddy Current Test Equipment in 0.420-in.-OD Tubing of the Type Proposed for Use in

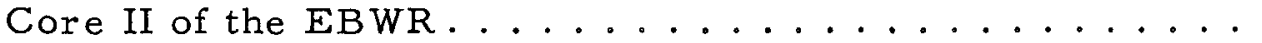

11 The Basic Geometrical Arrangement of the Through-

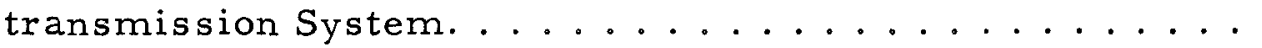

12 A Plot of Magnetic Field Intensity at the Location of the Pickup before and after a Metal Plate Is Inserted between

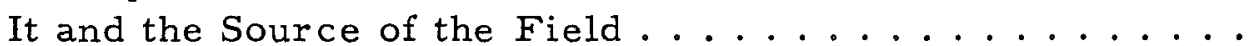

13 An Idealized Cross-sectional View of the Mask-Aperture Assembly ......................

14 A Mask-Aperture Assembly Used in the Through-

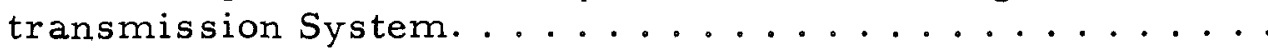




\section{LIST OF FIGURES}

No.

Title

$\underline{\text { Page }}$

15 Recordings Made from the Output of the Throughtransmission System While a Test Specimen Containing an Artificial Defect Was Being Scanned ...........

16 The Drop in the Peak Voltage Developed across the Pickup Coil When a Metal Is Inserted between the MaskAperture Assembly and Pickup Plotted as a Function of Aperture Size. The variable parameter is pulse length...

17 The Peak Induced Voltage in the Pickup Plotted as a Function of the Distance between the Axis of the Aperture and the Axis of the Pickup. The spacing between the mask and the pickup was maintained at $\frac{1}{8}$ in. Curve $A$ was obtained without the use of a blocking shim, and Curve B was obtained after the blocking shim was in place ......

18 Block Diagram of the Basic Through-transmission

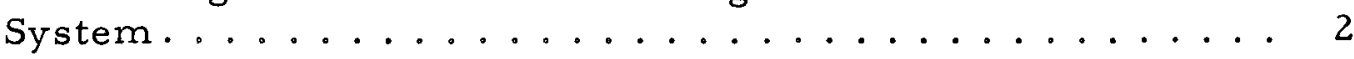

A Line Drawing of One Type of Mask-Aperture Assembly . .

20 A Set of Waveforms Obtained from Photographs of Oscilloscope Patterns Which Show Curves Obtained from the Output of the Pickup.................

21 The Amplified Positive Portion of the Voltage Waveform

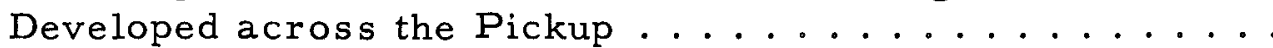

22 The Peak Value of the Voltage Pulse Induced in the Pickup, Plotted as a Function of the Distance between the Aperture and the Test Specimen. Metal resistivity is the variable

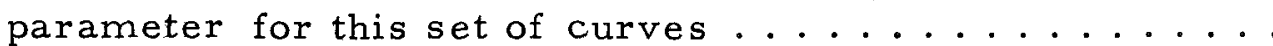

23 An Idealized Representation of the Short- and Long-pulse Waveforms as They Appear on an Oscilloscope Face . . . . 26 


\title{
PROGRESS REPORT ON NONDESTRUCTIVE TESTING BY ELECTROMAGNETIC METHODS
}

\author{
by
}

C. J. Renken

\section{INTRODUCTION}

This report summarizes new developments and improvements in electromagnetic and eddy current test methods and equipment. It is meant to be a continuation and outgrowth of the work reported in ANL-5861, A Status Report in Eddy Current Theory and Application.

\section{A DUAL-FREQUENCY EDDY CURRENT TEST SYSTEM WITH SOME APPLICATIONS}

A. Introduction

During the past several years, reactor components have been fabricated at Argonne which required metal tubing of a known quality level for their construction. It has been considered important to discover any defects in this tubing and to evaluate their possible harmfulness. This situation has required the use of a reliable nondestructive test, and electromagnetic test methods have and are being used for the inspection of considerable quantities of various types of metallic tubing.

The test system that has

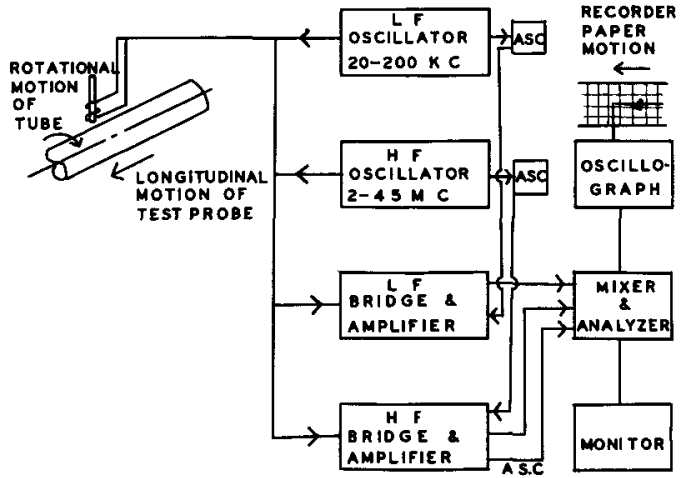

Figure 1. A Block Diagram of the Dual-Frequency Eddy Current Test System been used for most of this inspection work is a modified and improved version of the multifrequency eddy current testing system described in an earlier report. 1 The features of this equipment will first be described and the various specific applications together with test results will be discussed.

The block diagram of this system is shown in Figure 1. Two separate sinusoidal currents of widely separated frequencies are applied to the test probe. These

\footnotetext{
1
}

Renken, Myers, and McGonnagle, Status Report in Eddy Current Theory and Application, ANL-586 , (Nov 1958) p. 37. 
currents cause eddy current fields to be established in the metal. The apparent change in test probe impedance ${ }^{2}$ caused by these current fields provides useful information about the external and internal condition of the metal tube wall. These apparent changes, which are different at each frequency, are measured and converted to $A C$ voltages by 2 bridge networks. After amplification, each signal is then demodulated. The 2 lowfrequency signals which result from the demodulation processes carry the useful test information about the tube being inspected, as well as a large amount of extraneous information.

The high-frequency channel carries a frequency in the range of 1.5-4.5 Mc, depending upon the application. It is used to detect changes in probe-to-sample spacing, surface resistivity, and surface defects. The other channel operates at a much lower frequency, usually 20 to $200 \mathrm{kc}$, again depending upon the application. It is sensitive to all the previously mentioned effects plus conditions inside the tube, such as cracks and laps. The high-frequency channel also possesses a theoretical sensitivity to defects inside the tube wall, but this sensitivity is insufficient to interfere with the practical operation of the equipment.

The low-frequency signals which result from the demodulation processes in both channels are fed to a mixer section. Here, extraneous test information is eliminated and a signal sensitive to defects in the tube wall which occur over a short interval of time is supplied either to an oscilloscope or to an audio monitor.

Most eddy current test systems which are to be used for the testing of tubing come equipped with encircling-type test coils. In this case, mechanical scanning of the tube is effected by simply transporting the tube through the center of the coil. Such an arrangement allows high inspection speeds, but it severely limits the test-coil resolution which can be obtained, since the test coil must "view" the entire tube circumference at once. The use of an encircling coil in the applications which will be described later was impractical because of the limited resolution of this method. More will be said on this subject when these applications are discussed.

The test probe in the equipment described in Reference 1 consisted of a single, ferrite-cored pickup coil, but the test probe designed for tubing inspection is made of 2 ferrite-cored solenoids of $0.050-\mathrm{in}$. OD, which are located immediately adjacent to each other on a line parallel to the longitudinal axis of the tube. Each small coil carries one of the test frequencies. The magnetic coupling between them is reduced, by the insertion of a copper shim between the coils, to a level which is not troublesome. The reason

\footnotetext{
2 Ibid., p. 8
} 
a double-element test probe is used instead of a single-element design can best be understood by the consideration of the influence of a special type of defect on each type of test probe.

Consider a defect like a lap which opens to the outer surface of the tube and then runs into the wall at a shallow angle to a tangent on the outer circumference at the defect outlet. In this case, both channels will produce signals from the flaw opening on the surface, but as the deeper part of the flaw passes under the probe, only the low-frequency channel will detect an abnormality. If a single-element test probe is being used, the resultant signal from both channels in the mixer section will be a lowfrequency signal which will not pass through the narrow pass band of the mixer section. This will not happen when a 2 -element probe is being used, since such a defect will not pass under each element simultaneously. The resultant signal in this case will be a sharp pulse which will easily pass through the mixer pass band. The test probe is potted in a stainless steel jacket and, during scanning, is maintained a nominal $0.010 \mathrm{in}$. from the tube. The test system electronically adjusts to probe-to-metal spacing variations from 0 to 0.030 in.

Various mechanical arrangements have been used to produce the motion necessary for a complete inspection of the tube. In every case the tube is caused to spin and either pass under the probe, or else the probe is passed over the tube. In either case, the projection of the probe upon the tube describes a spiral path around the tube of no greater than $\frac{1}{16}-$ in. pitch. The rotational speed of the tube depends upon the tube diameter, and whether or not a permanent recording of tube quality is necessary. If the audio alarm is used with this system, and, as an example, a $\frac{3}{8}-$ in.-OD tube is being inspected, rotational speeds up to $900 \mathrm{rpm}$ are possible. But if a permanent recording is necessary and the recording equipment has a bandwidth of $60 \mathrm{cps}$, maximum rotational speed for this example is $210 \mathrm{rpm}$ and probe relative motion along the tube axis is limited to about $2 \mathrm{ft} / \mathrm{min}$.

\section{B. Eddy Current Tests on Tubing for Core IA of the EBWR}

The first samples of tubing for Core IA of the EBWR which arrived from the supplier showed that a nondestructive test of some type was necessary, at least to sort out the worst part of the tubing. This tubing, of nominal 0.375-in. OD, 0.022-in. wall and 78-in. length, was afflicted with a considerable number of serious radial cracks which started from the ID. A metallographic section of a tube, No. 2644, showing such a crack is shown in Figure 2 .

The dual-frequency test equipment described in Reference 1 was hastily modified for application to this problem. 


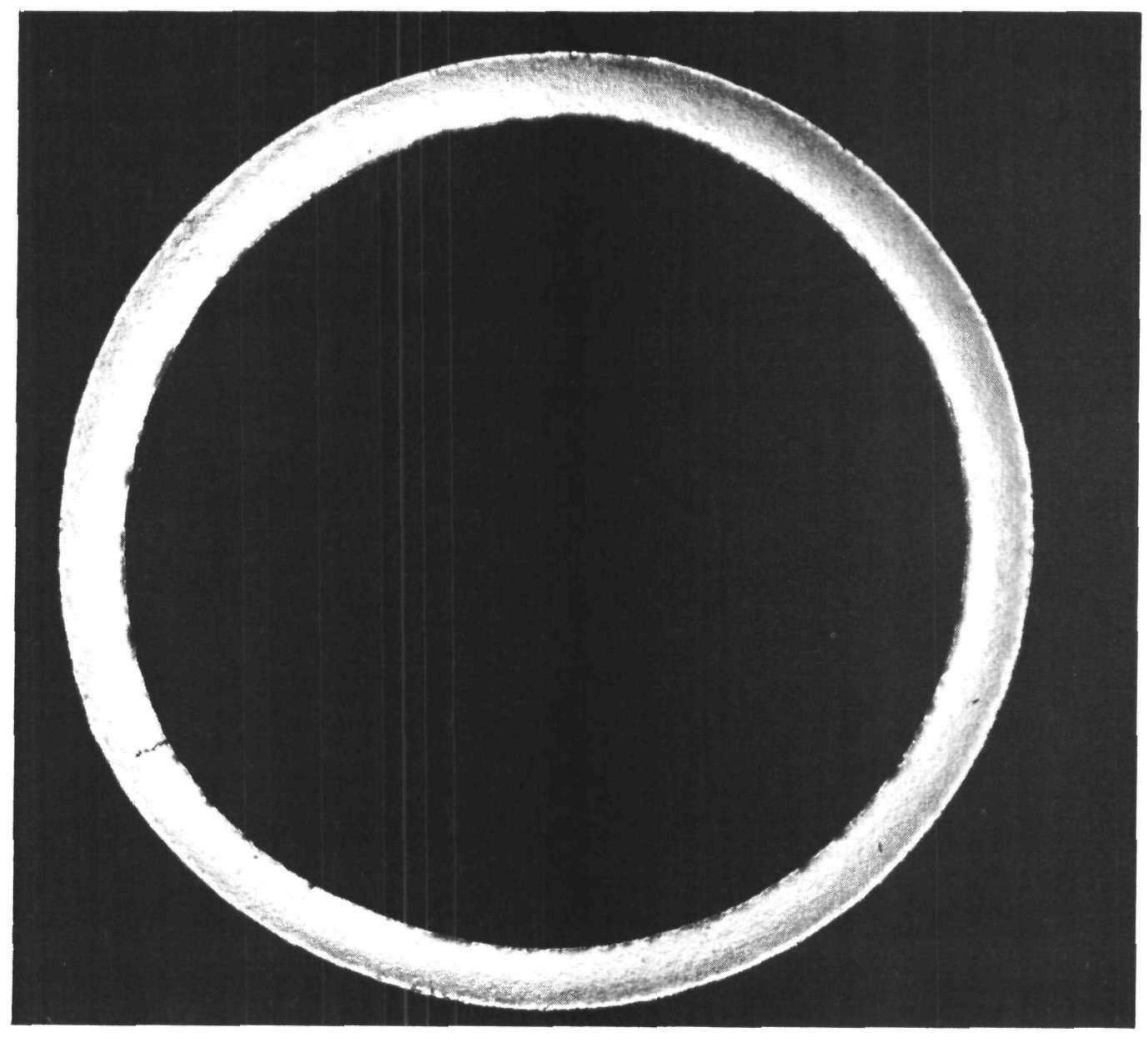

27410

$10 X$

Figure 2. A Microphotograph of a Cross Section of the Tube at the Point Marked 105a in Figure 3

A section of the oscillograph recording produced by this test equipment when tube No. 2644 was tested is shown in Figure 3. Wide excursions of the pen represent the deepest cracks. Note the presence of other cracks showing on this section of the recording. It was found that, subject to certain conditions which will be mentioned shortly, good correlation between crack depth and amplitude of the recorded signal existed. In the trace shown in Figure 3, a $\frac{1}{4}$-in. pen deflection represented a 0.004-in.deep crack starting from the ID.

It was decided to accept all tubes having cracks shallower than this value. A suitable standard was obtained to allow the operator to check the instrument sensitivity from time to time. Under this criterion, about $60 \%$ of the 2500 tubes inspected were accepted. If the acceptable crack depth had been 0.002 in. instead of 0.004 in., very little of the tubing would have been available for use. However, it is doubtful if the test equipment available at that time would have reliably detected cracks of 0.002 in. and less.

All defects have more than one dimension, and the length along the axis as well as the width and depth affect the test instrument. A crack having a vanishingly small width, that is, nearly perfect metal-to-metal contact across the crack, would not be detected at all. 


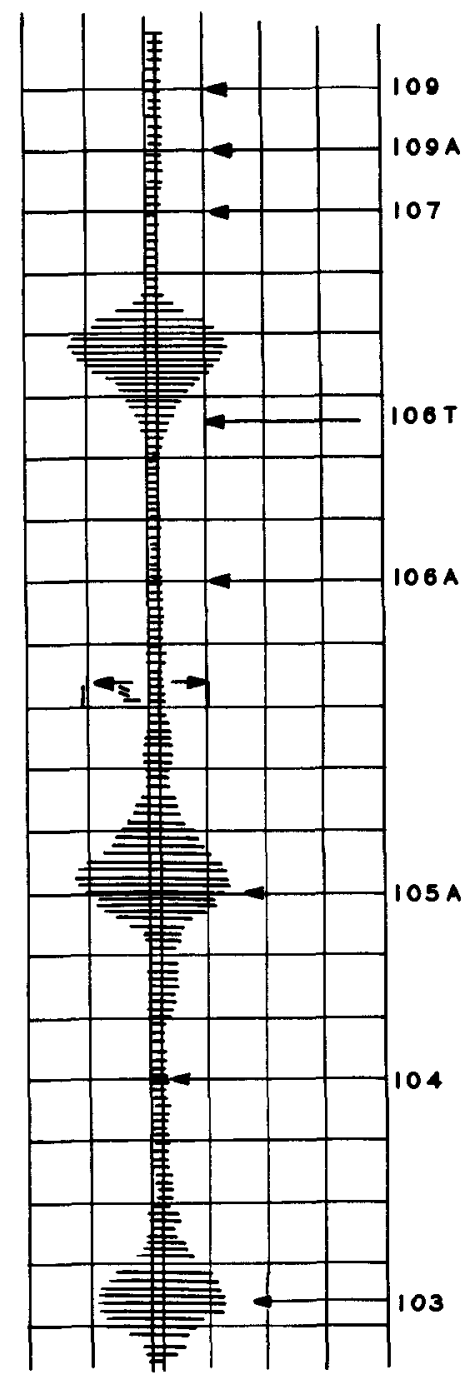

Figure 3

Part of the Trace Obtained from the Inspection of Tube \#2644. A deflection of $1 / 4 \mathrm{in}$. represents about a $0.004-$ in. crack.
In this particular test problem, the instrument calibration was reliable only for cracks longer than $\frac{1}{16}$ in. along the tube axis. If a crack was less than $\frac{1}{16}$ in. long, the output signal from the test equipment did not give a true indication of crack depth because of the limited resolution of the test probe. Fortunately, the cracks discovered in these tubes were generally at least $\frac{1}{4}$ in. long. Two small cracks a few degrees apart could, and probably did, on occasion appear as one large crack and thus cause the rejection of a few tubes. Despite these considerations, an extensive comparison of recordings from the test equipment with metallographic sections showed that the recordings produced a satisfactory record of the prevalence and depth of cracks in these tubes.

Some attempts were made to inspect the Zircaloy-2 tubing for core IA of the EBWR with a test system equipped with an encircling coil. This would have provided the advantage of a much higher speed of inspection. None of these attempts worked for various reasons: either the equipment did not have enough sensitivity, or it had too much sensitivity to the wrong test variable, or because of the integrating effect of the encircling coil a number of small defects appeared upon its output as one large defect. This would have caused the rejection of too much usable tubing.

C. The Inspection of the $2 \frac{1}{4} \%$ Croloy Tubing for the EBR-II Heat Exchangers

Large quantities of $2 \frac{1}{4} \%$ chromium steel heatexchanger tubing of OD from 1.573 to $0.528 \mathrm{in}$. were inspected in lengths of about $28 \mathrm{ft}$ by a dual-frequency test system. The primary test of this material was accomplished by an ultrasonic method, but the eddy

current test was operated simultaneously to detect laps and other defects close to the surface which were not easily detectable by ultrasonics. The frequencies used in these tests were 47.5 and $2000 \mathrm{kc}$. Because of the ferromagnetic nature of Croloy, electromagnetic tests using such high-frequency fields are sensitive only to those discontinuities which are located a short distance below the surface. But the eddy current equipment did possess great sensitivity to flaws, such as those shown in Figures 4 and 5 . An audio alarm indicated when a defective area was passing under the test probe. About $5 \%$ of the Croloy tubes were rejected for defects discovered by the eddy current test equipment. 


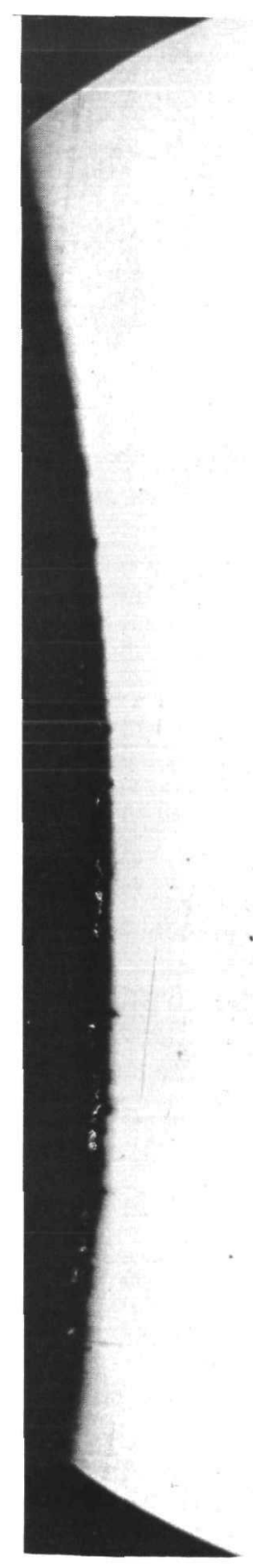

24742

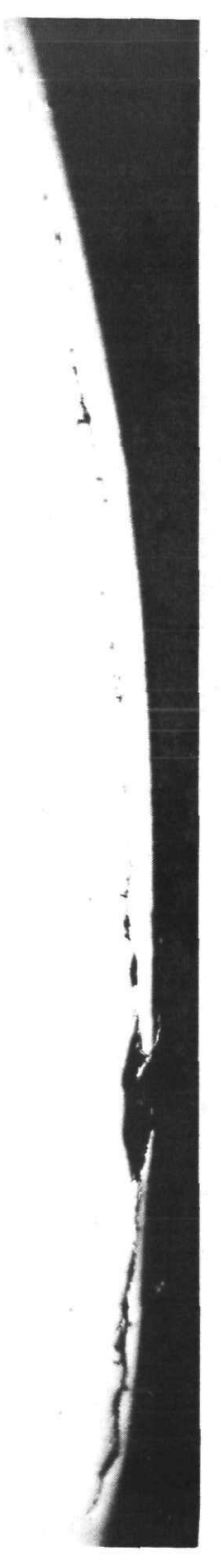

50X

Figure 4. A Lap Detected in Croloy Heat Exchanger Tubing by the Eddy Current Test Equipment

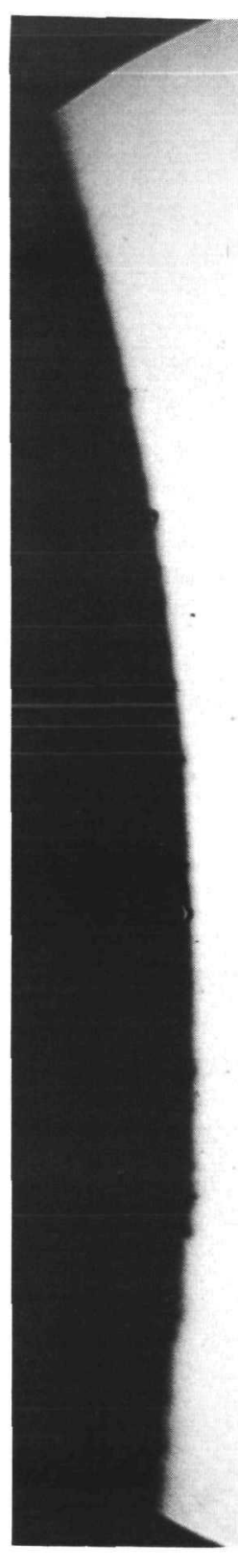

24743

Figure 5. Another Lap Detected in Croloy Heat Exchanger Tubing by the Eddy Current Test Equipment 
D. Eddy Current Tests on Stainless Steel Tubing for Use in the EBR-II Blanket

Samples of the stainless steel tubing intended for use in the EBR-II blanket fuel elements were tested with a dual-frequency sinusoidal test system at frequencies of 35.5 and $456 \mathrm{kc}$. Small quantities of both welded and seamless tubing of nominal $0.493-\mathrm{in}$. OD and 0.025 -in. wall were inspected. Because only a sample of this tubing was being inspected, no standards were adopted; instead, any abnormal indication produced by the test system was cause for rejection of that tube. Reject rates for seamless tubes about $6 \mathrm{ft}$ long were in the range of a few per cent. Most of the rejected tubes failed because of inclusions or out-of-tolerance wall thickness. A few tubes were rejected for what later proved to be nonhomogeneous alloy composition. The inspection of welded stainless steel tubing yielded occasional rejections for bad welds; on the other hand, abnormalities of wall thickness were rarer.

E. Tests of Zircaloy-2 Tubing Intended for Use in the EBR-I Mark-IV

This Zircaloy-2 tubing, of nominal 0.299-in. OD and $0.257-$ in. ID was tested in lengths of approximately $80 \mathrm{in}$. by the improved version of the equipment used to test the Zircaloy-2 tubing of Core IA of the EBWR. This is the model currently in use. The frequencies used during these tests were 65 and $1750 \mathrm{kc}$, which seemed to be slightly better for this test problem than the frequencies used with the older equipment. The now-familiar radial cracks, such as the one shown in Figure 6, were discovered in a number of tubes, and, in addition, a somewhat different type of flaw occasionally was encountered.

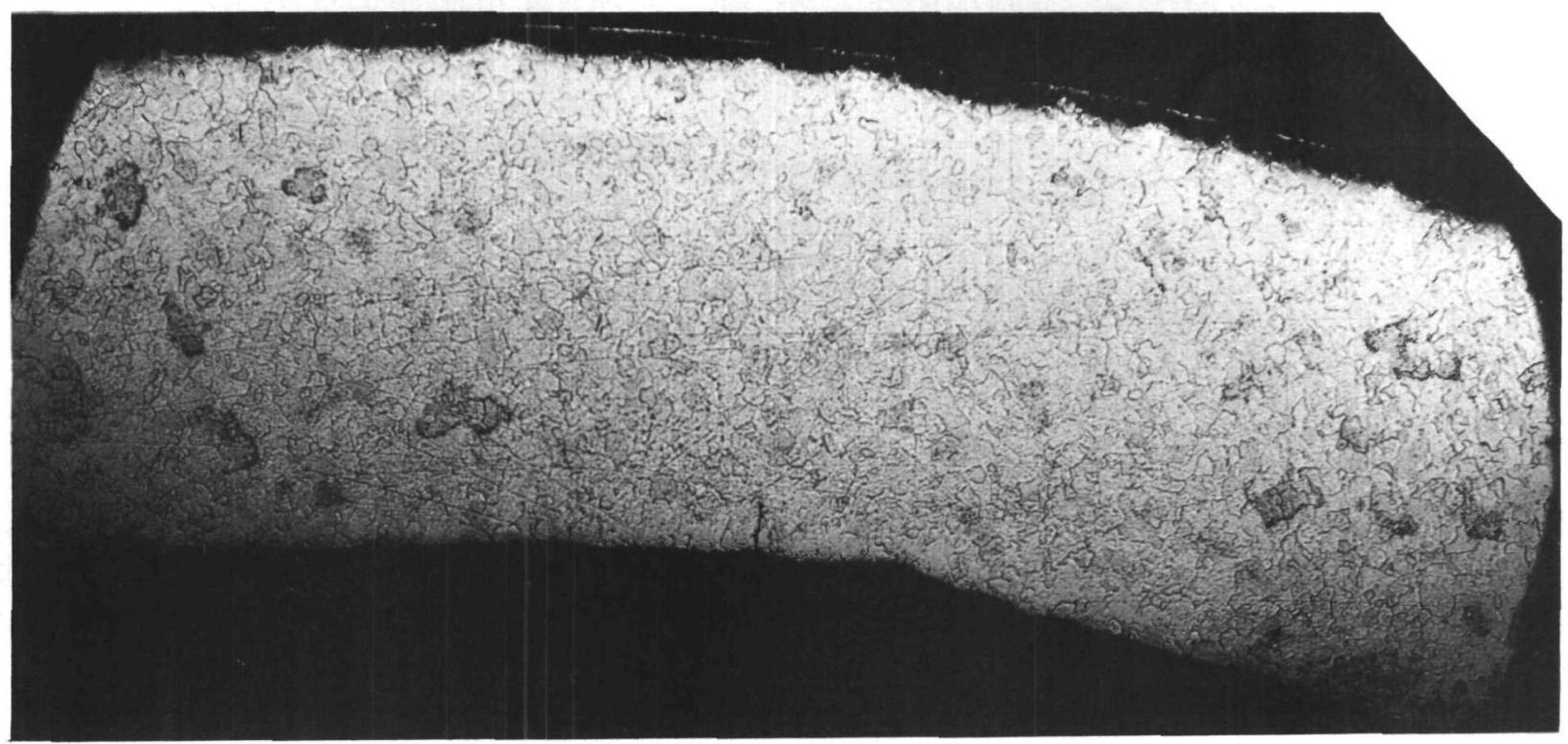

30495

Figure 6. A Typical Small Radial Crack Often Seen in Small-diameter Thin-wall Zircaloy-2 Tubing

${ }^{3}$ The tubing discussed in this section was obtained from an outside supplier. Other tubing for this application is being produced at Argonne, and tests are still in progress as of this writing. 
One of these is shown in Figure 7. This type of defect was found running parallel to the tube circumference as well as radially and at all angles in between these extremes. Whether faults of this type were prevalent in previously tested Zircaloy-2 tubing is not known, because it was definitely determined that the older equipment did not detect this type of flaw. Tubes which showed this type of formation were somewhat arbitrarily rejected, based on the same reject level as was applied in the case of the tubing used in Core IA of the EBWR. Best judgment seemed to indicate that defects of the type shown in Figure 7 did not belong in the EBR-I Core IV, even though it was not determined exactly what caused these flaws, or if they were, in fact, deleterious. The reject rate on this tubing was approximately $25 \%$.

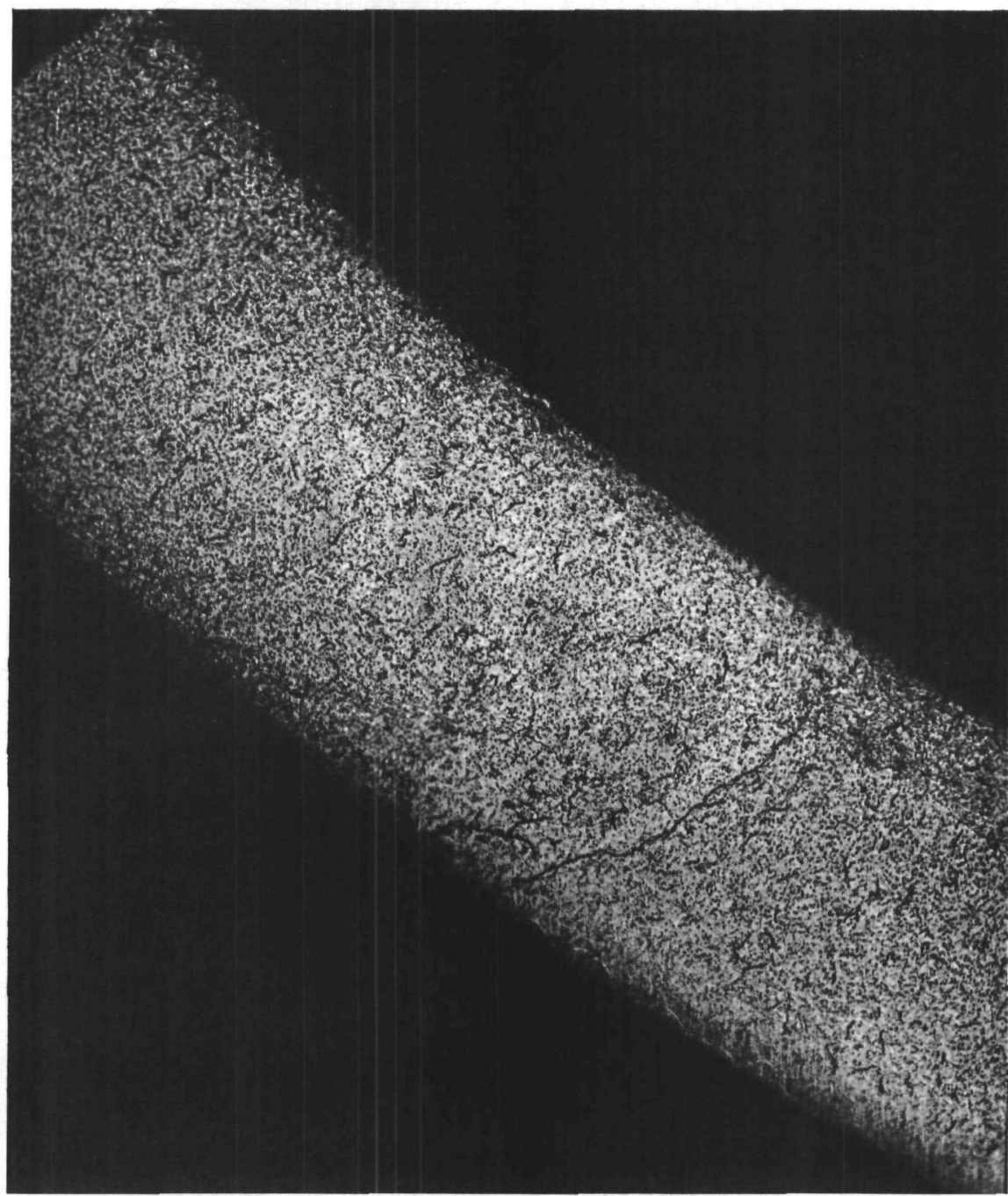

Figure 7. A Flaw Detected in 0.299-in. Zircaloy-2 Tubing. The tube wall has been nearly completely penetrated. This specimen has been very heavily etched to make the defect more obvious. 
F. An Evaluation of the Quality of Zircaloy-2 Tubing of the Type Proposed for Use in the EBWR Core II

The improved version of the dual-frequency eddy current test equipment, mentioned in the previous section, was used to evaluate the quality of tubing proposed for use in Core II of the EBWR. Approximately $125 \mathrm{ft}$ of sample tubing of nominal 0.420 -in. OD and 0.025 -in. wall were submitted by each of 5 different fabricators. The reject level for purposes of this evaluation was adjusted to cause the rejection of a tube if any abrupt localized reduction of wall thickness of over 0.002 in. extending over $\frac{1}{16} \mathrm{in}$. along the axis occurred. The practical effect of any rejection level stated in this manner is to cause the rejection of more serious faults which occur over a smaller distance as well as defects in the wall which produce an equivalent signal. The tubes were tested in lengths of approximately $6 \mathrm{ft}$, and the percentage of tubes rejected varied from none at all in the case of one supplier to $31.5 \%$ in the case of another. Figures 8,9 , and 10 show microphotographs of some defects discovered in this tubing by the eddy current test equipment. It can be inferred from these and earlier microphotographs that a wide variety of defects occur in small-diameter Zircaloy- 2 tubing. 


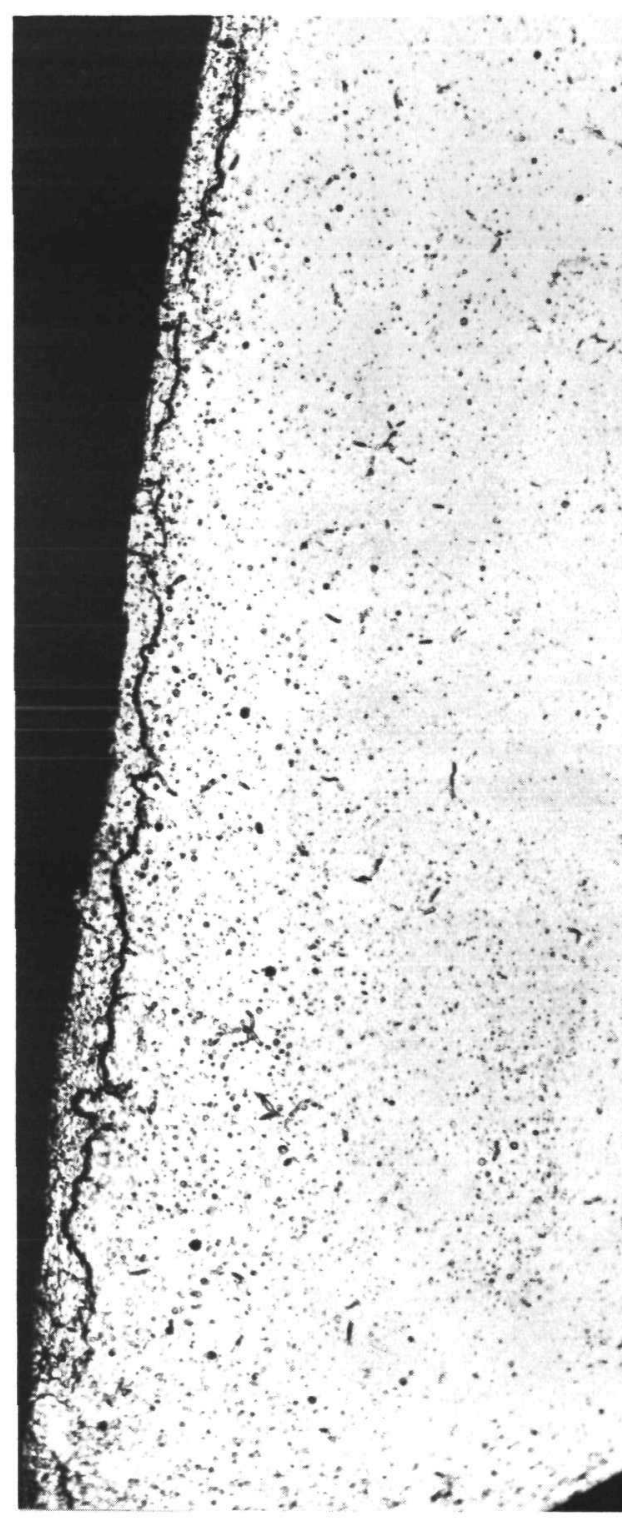

32307

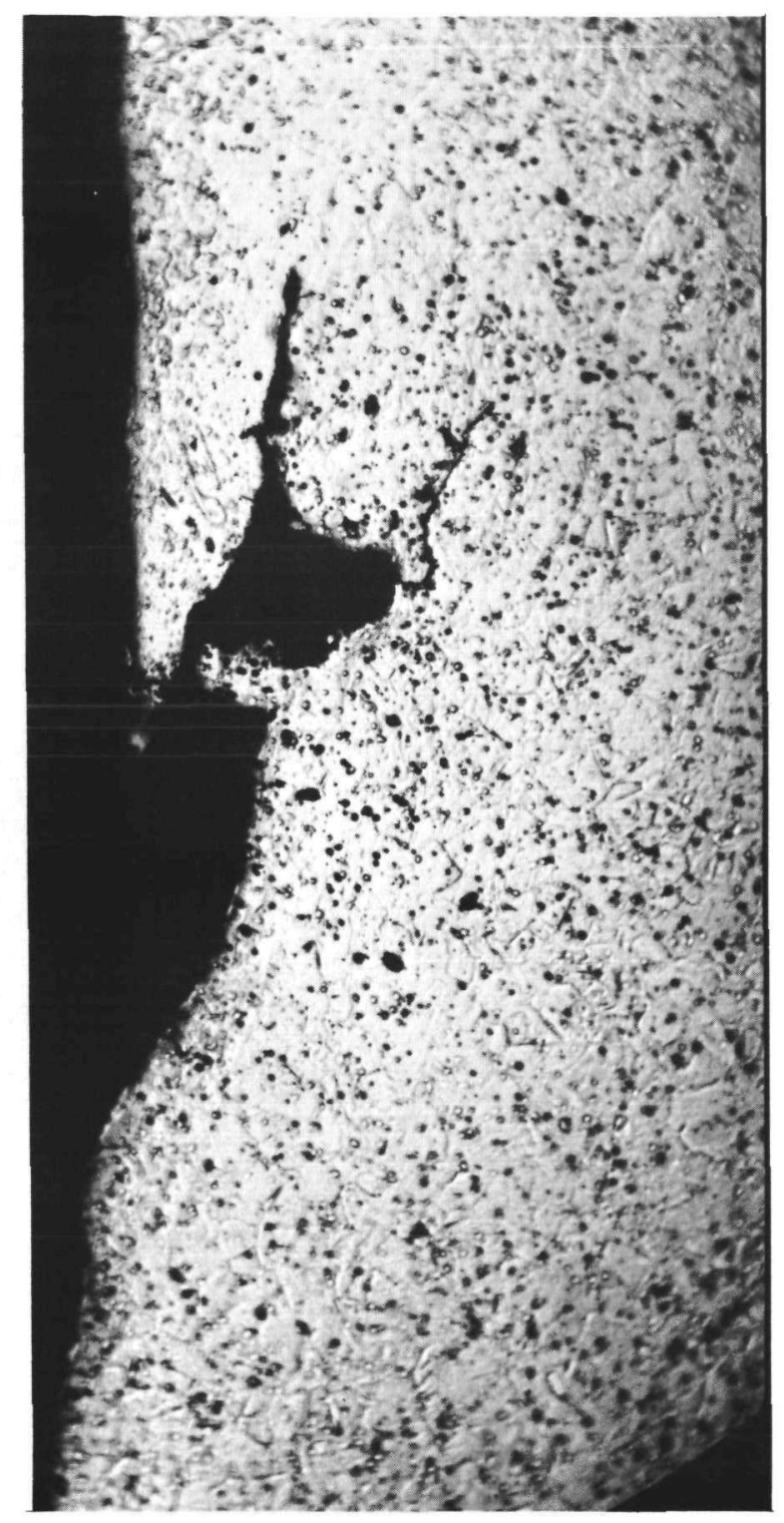

250X 32309

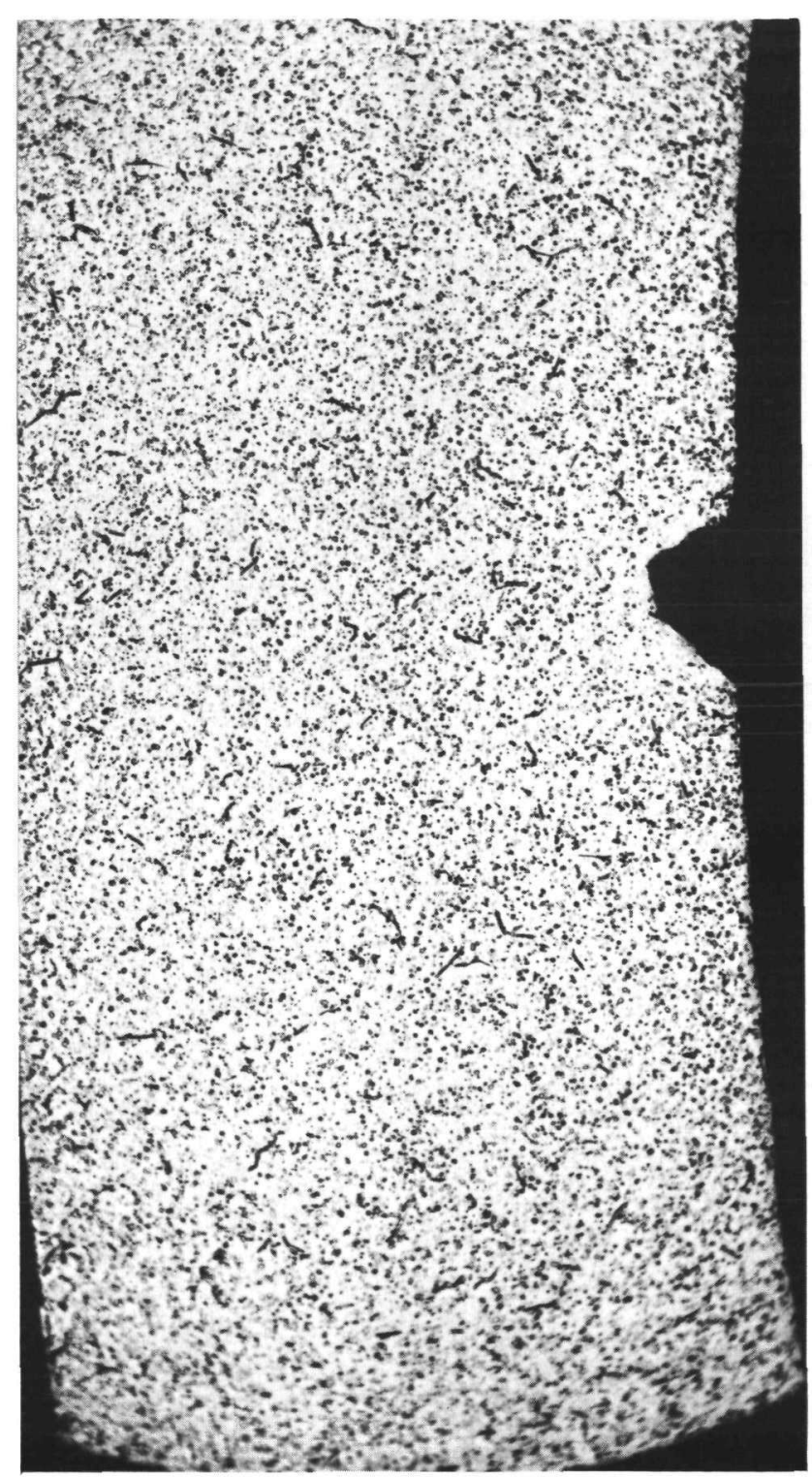

$250 \mathrm{X} \quad 33489$

$250 X$
Figure 8. Defects Detected by the Eddy Current Test Equipment in 0.420-in.-OD Tubing of the Type Proposed for Use in Core II of the EBWR
Figure 9. Defects Detected by the Eddy Current Test Equipment in 0.420-in.-OD Tubing of the Type Proposed for Use in Core II of the EBWR
Figure 10. Defects Detected by the Eddy Current Test Equipment in 0.420-in.-OD Tubing of the Type Proposed for Use in Core II of the EBWR 


\section{A THROUGH-TRANSMISSION SYSTEM USING PULSED EDDY CURRENT FIELDS ${ }^{4}$}

\section{A. Introduction}

Electromagnetic test techniques which depend on the transmission of an eddy current field through a metal are not new, but they have not been used frequentlybecause the advantages these techniques offered were insufficient to justify the increased mechanical inconvenience. This inconvenience stems from the fact that the coil which generates the field is mounted on one side of the metal, while the coil which detects the field passing through the metal is mounted on the other side, as shown in Figure 11. Through-transmission techniques have been used to measure the thickness of metal shims, 5 but the extremely high attenuation of highfrequency eddy current fields in good conductors requires the use of large coils, low frequencies, and high power. Large coils and low frequencies practically guarantee poor resolution, so that other nondestructive testing techniques which can operate from one side only have generally proved to be more useful solutions to the problems which otherwise suggest the use of a through-transmission technique.

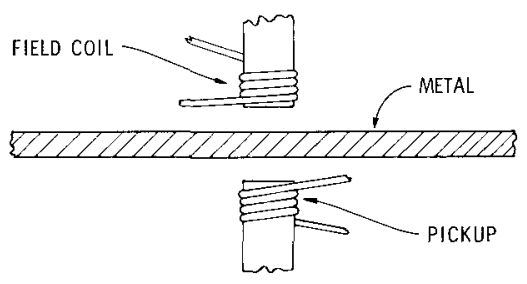

Figure 11. The Basic Geometrical Arrangement of the Through-transmission System

\section{B. Diffusion of Current Fields in Good \\ Conductors}

In the situation shown in Figure 11 , a time-varying current flowing in the field coil will cause an induced voltage to appear at the terminals of the pickup. If the current varies sinusoidally, the amount the voltage is attenuated when the metal is inserted between the 2 coils is given approximately by 6

$$
\operatorname{drop}(\mathrm{db})=10 \log \left[\left(\frac{\mathrm{AT} \gamma \mathrm{F}}{78.8}\right)^{2}+1\right] \text {, }
$$

where

$$
\begin{array}{ll}
\mathrm{A}=\text { coil radius, } \mathrm{cm} & \mathrm{F}=\text { frequency } \\
\mathrm{T}=\text { metal thicknes }, \mathrm{cm} & \gamma=\text { specific conductivity. }
\end{array}
$$

${ }^{4}$ Some of the material in this section of the report has already appeared in the Nondestructive Testing Journal, 18, No. 4, p. 234.

5Colten, Robert B., Noncontacting Gages for Nonferrous Metals, Electronics, March 1956, p. 171.

${ }^{6}$ Levy, Samuel, Electromagnetic Shielding Effect of an Infinite Plane Conducting Sheet Placed between Circular Coaxial Coils, Proc. Inst. Radio Engrs., 24, 7.6, p. 923. 
If the current in the field-generating coil is a more complicated function of time, as for example a pulse, then the already sufficiently complicated question of field attenuation becomes even more difficult, and so far seems to have escaped an exact analytical solution.

The diffusion of pulsed-current fields into good conductors has been discussed in an earlier report, 7 and various source references are given there. Only a few pertinent points of that discussion will be mentioned here. A sinusoidal current field flowing in a good conductor will also undergo an increasing lag in phase as it diffuses into the conductor, and a pulsed-current field will experience an apparent delay in its passage across the thickness of the metal. If a so-called signal velocity is defined as the thickness of the metal divided by the time delay of the main bundle of energy during its passage across the thickness, it is found that experimental values of signal velocity are quite low compared with the propagation velocities of other electromagnetic disturbances. Figure 12 shows the results of experimental measurements of magnetic field intensity at the location of the pickup coil before and after a piece of $\frac{5}{64}$-in. 304 stainless steel plate was inserted between it and the source of the field. A rough calculation in this case yielded a signal velocity of about $280,000 \mathrm{~cm} / \mathrm{sec}$. In a better conductor, the velocity would be even lower. So both the velocity and attenuation of a current field diffusing through a conductor are dependent on the effective conductivity of the path of the current field, and this effective conductivity is influenced not only by the actual conductivity of the metal, but also any defects or other discontinuities which might lie in the field.

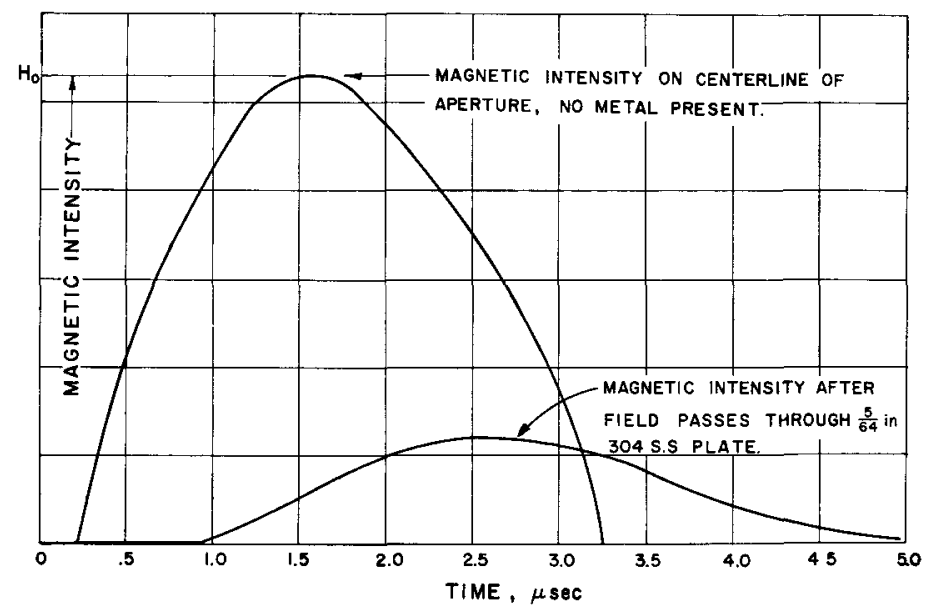

C. The Use of Pulsed Fields
Figure 12

A Plot of Magnetic Field Intensity at the Location of the Pickup before and after a Metal Plate Is Inserted between It and the Source of the Field

Pulsed fields have this obvious advantage over steady-state fields in this application: if a short-duty cycle is used, very high peak-pulse powers can be attained without exceeding the continuous power-dissipation

${ }^{7}$ Renken, C. J., The Diffusion of Pulsed Current Fields in Good Conductors, ANL-6346, Symposium on Physics and Nondestructive Testing, October, 1960, pp. 127-38. 
capabilities of a relatively small field coil. This makes the throughtransmission method useful with thicker sections than could otherwise be tested, and also makes possible a second important feature of the throughtransmission method, which will be described in the next section.

D. The Use of Masks to Obtain Improved Resolution

Experimenters in the field of nondestructive testing have expended a considerable amount of effort on attempts to obtain increased resolution with test systems. No attempt will be made here to define resolution exactly as applied to an electromagnetic test system, but the term refers to the ability of the equipment to separately detect defects which occur close together in a metal. For example, other things being equal, a $0.010-$ in. inclusion some distance under the surface of a metal will be detected easier by a $\frac{1}{16}$-in. diameter probe than by a $\frac{1}{2}$-in.-diameter probe because the larger probe averages the information it receives over so much more area. So most efforts toward better resolution have involved the construction of smaller and smaller ferrite-cored test probes, or the use of flux guides, or both. There is a lower limit on the size which a test probe can be made and still retain enough inductance to produce a usable signal. Because of stray flux, a point of diminishing returns is eventually reached beyond which a smaller probe produces no worthwhile increase in resolution. Probes smaller than those mentioned in the first section of this report have not been found practical. It has been found that, through the use of special masks, the induction field from the field-generating coil can be restricted to a small cross-sectional area over a path in space long enough to be useful for the practical purposes of nondestructive testing.

An idealized drawing of such a mask with the field-generating coil in it is shown in Figure 13. The design of these masks so far has been an intuitive and empirical matter, although a considerable amount of experimental data has been accumulated which will be published in a later report. What is really needed is a theoretical analysis of the factors affecting the design of such a mask, but preliminary attempts in this direction indicate that this would be a boundary-value problem of considerable difficulty. It would probably be necessary to make so many idealizing as sumptions that the analysis in the end would be valueless for design purposes.

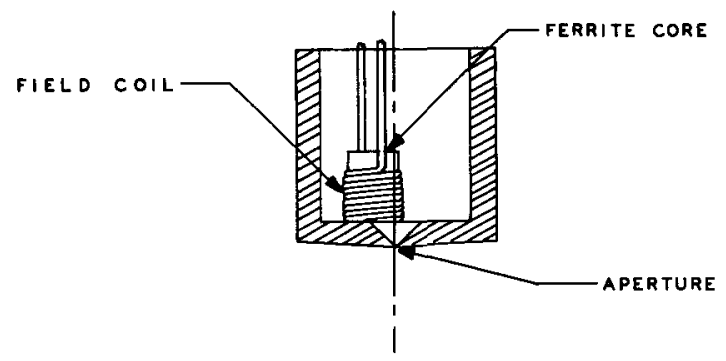

Figure 13

An Idealized Cross-sectional View of the Mask-Aperture Assembly 
Figure 14 shows one of these masks. The thickness of the mask wall necessary depends upon the pulse lengths employed, but practically no energy should be transmitted through the face of the mask except through the aperture. The apertures that have been used in these masks range in diameter from 0.030 to $0.063 \mathrm{in}$. Most of the power in the field generated by the field coil is expended in $I^{2} R$ losses in the walls of the mask, but this is part of the price paid for improved resolution. An indication of how much the resolution is improved is shown in Figure 15.

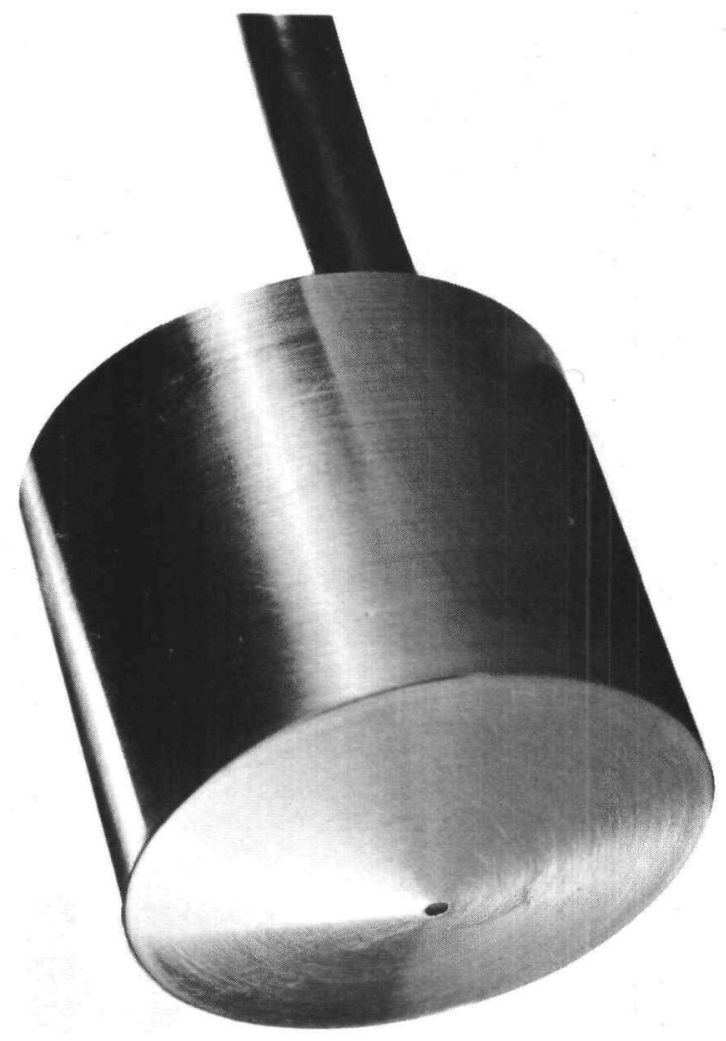

Figure 14

A Mask-Aperture Assembly Used in the Through-transmission System
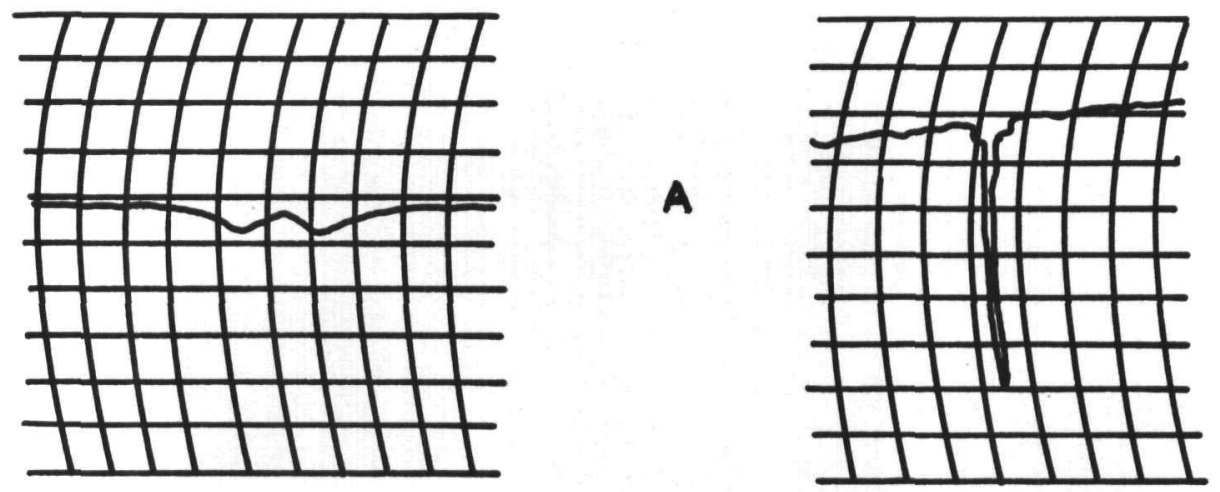

Figure 15. Recordings Made From the Output of the Through-transmission System While a Test Specimen Containing an Artificial Defect Was Being Scanned. The test specimen in this case was a 0.035-in.-thick Al plate with a 1/16-in. hole drilled through it. Trace (A) was obtained using the 1/4-in. field coil alone and trace (B) was obtained when the field coil was enclosed in a mask with a 1/16-in. aperture. The distance between aperture and metal for trace (B) was maintained the same as the distance between field coil and metal for trace (A). Recording and scanning speeds were maintained constant. For these tests, $5-\mu$ sec pulses were used. 
It is possible to locate the pickup coil, instead of the field-generating coil, in the mask. This arrangement seemed to produce results equivalent to the opposite situation, but was not investigated as thoroughly for 2 practical reasons. One was that the copper of the mask served as a useful heat sink for the power being dissipated in the field-generating coil. The other was that experiments were already in progress on a pulsed-field reflection system (discussed in the next section), and in this method the fieldgenerating coil must be in the mask-aperture assembly.

E. Experimental Data on the Field around the Aperture

An examination of the results of Levy's analysis showed that the drop in the received signal when a metal is introduced between the field coil and the receiving coil is a function of coil area. This effect is also observed as a function of aperture area when pulsed fields and a maskaperture assembly are being used. Figure 16 shows the signal drop experienced as a function of aperture size with pulse length as the variable parameter. The aperture contours of the different masks were as close to identical as possible, but a change in aperture size must change the aperture contour in some degree at its most constricted zone. A piece of 16 gauge 304 stainless steel served as the metal in this experiment.

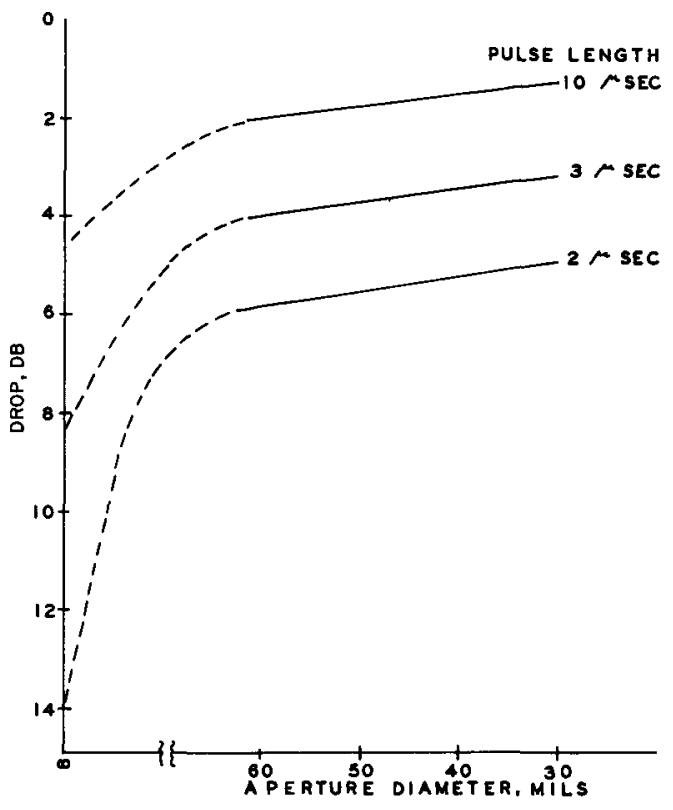

Figure 16. The Drop in the Peak Voltage Developed Across the Pickup Coil When a Metal Is Inserted between the Mask-Aperture assembly and Pickup Plotted as a Function of Aperture Size. The variable parameter is pulse length.
Some idea of the variation of the field with distance from the aperture can be gained from Figure 17. Curve A was obtained by passing a small pickup coil along a line bisecting the aperture at a fixed distance above the aperture; this distance was great enough so that the flux already fringed over a much greater area than covered by the aperture. The important point is that the voltage (curve A) induced in the pickup passed through a null and changed phase as the aperture was crossed. This change in polarity can be eliminated and the flux on one side of a line bisecting the aperture can be concentrated by the use of a so-called blocking shim. This item is a small thin segment of material of good conductivity coated on one side with an insulating material. It is placed on the face of the mask near the aperture. The value of this device can be seen from curve $B$ of Figure 17 . An explanation of the theory of operation and proper design of this device will not be undertaken here. 


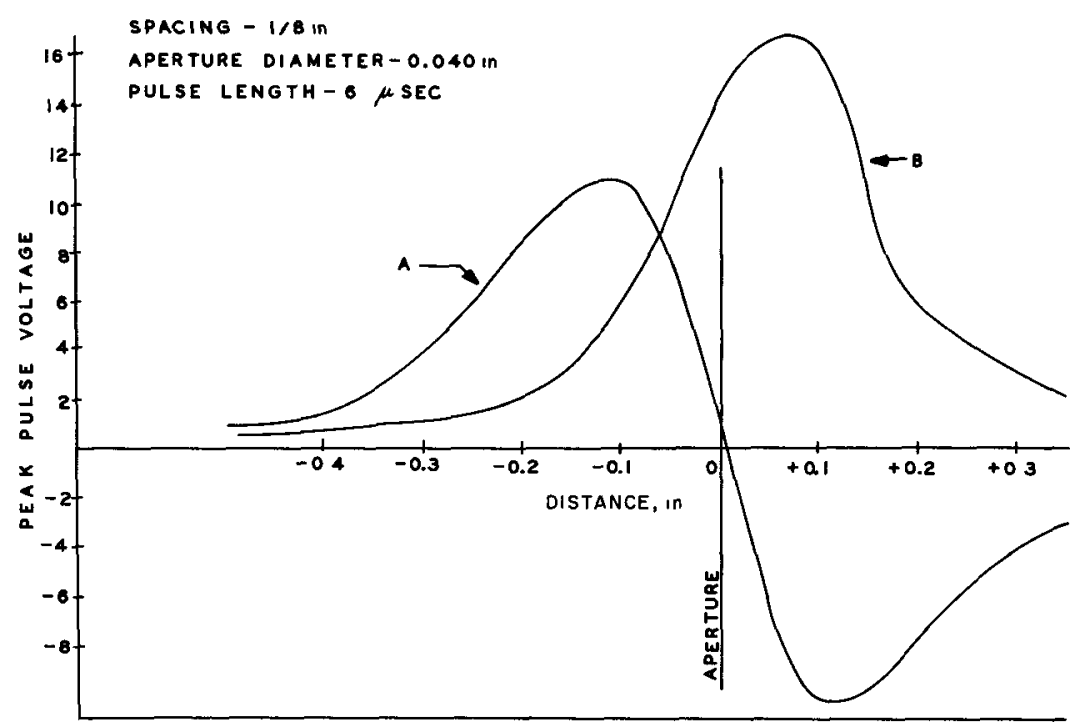

Figure 17. The Peak Induced Voltage in the Pickup Plotted as a Function of the Distance between the Axis of the Aperture and the Axis of the Pickup. The spacing between the mask and the pickup was maintained at $1 / 8 \mathrm{in}$. Curve $A$ was obtanned without the use of a blocking shim, and curve $B$ was obtamed after the blocking shim was in place.

F. Block Diagram

Figure 18 shows a block diagram of the basic through-transmission system. The amplitude of the received signal is somewhat sensitive to the distance between mask and test specimen. In applications for which this effect is troublesome, the amount of time the pulse is delayed while traveling through the metal can be measured electronically. This method for obtaining information about the interior of the specimen is much less sensitive to the location of the test specimen between mask and pickup.

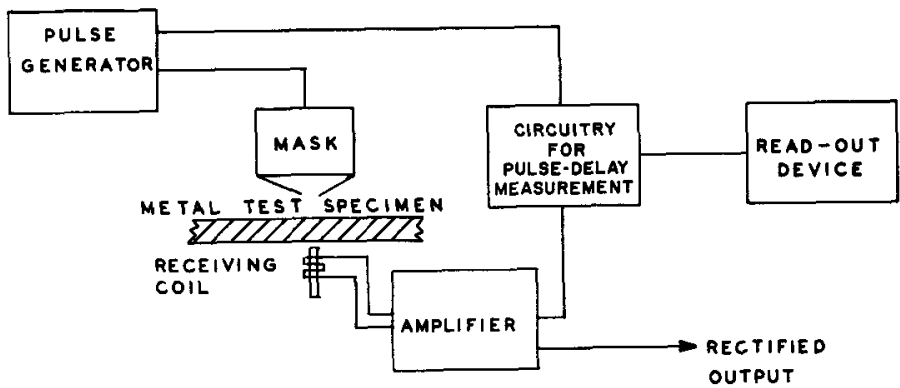

Figure 18

Block Diagram of the Basic

Through-transmission System

The through-transmission method is logically applied to certain test problems which are especially difficult to solve with conventional eddy current test methods. It has been, for example, successfully used on a quantity of aluminum alloy tubes of $0.375-\mathrm{in.} O D$ and $0.022-\mathrm{in}$. wall. In this case the pickup was mounted on a rod which passed through the center of the tube. 
G. Possible Applications

With this method relatively thick sections can be tested with good resolution when with conventional techniques it would be necessary to resort to very low frequencies which practically always produce poor resolution. The through-transmission technique which uses a maskaperture assembly to improve resolution should serve as a useful supplement to present methods of electromagnetic testing. 
IV. A PULSED-FIELD REFLECTION SYSTEM WHICH USES FIELDS OF SMALL CROSS-SECTIONAL AREA

A. Introduction

It has been found possible to use fields and the mask-aperture assemblies mentioned in the previous section in a test arrangement which permits the inspection of the test specimen to be accomplished from one side only. This duplicates the convenience of the conventional eddy current test equipment, yet preserves the circuit simplicity and surface resolution of the through-transmission system described in the previous section.

B. The Reflection of Time-varying Electromagnetic Fields from Good Conductors

A time-varying electromagnetic field impinging upon a good conductor is nearly completely reflected. A small fraction of the energy, however, does enter the conductor and diffuses into it. Discontinuities in the conductor which cause a localized change in resistivity, or permeability, or both will cause a partial reflection of the current field. These reflections travel back up to the surface and appear outside as a field which can be detected and used for the purposes of nondestructive testing. A more complete discussion of this subject is given in Reference 7, previously cited.

The concept of inductive fields being reflected from the surfaces of good conductors and also from internal discontinuities is perhaps not as familiar to researchers in the field of electromagnetic testing as are the concepts of the impedance plane, nominal depth of penetration, and apparent test-coil impedance, which are traditional in papers relating to sinusoidal eddy current test phenomena and methods. Confusion of the pulsed-field terminology with the terminology of ultrasonic nondestructive test techniques is possible.

In the present case, the time elapsed between emission of the pulse and the reflection from the surface is much too short to be observed experimentally. Reflections from discontinuities inside the metal do not exist as discrete pulses which are identifiable in time, but they are invariably buried in the normal reflections which are received from metal surface and interior. This is the behavior expected from a field traveling in a dispersive medium and is dealt with in more detail in the references previously cited. It should also be recognized that the phenomena occurring in both the pulsed-field and the more familiar sinusoidal cases are the same, despite the difference in terminology. The changes of reflected impedance which occur in a test coil carrying sinusoidal current when a good conductor is brought into proximity can be considered as being due to the effect of an infinite wavetrain of steady state reflections of the induced field from the 
metal surface and interior. The impedance plane concept in its present state of development is too clumsy to be useful when the current fields in question are not varying sinusoidally in time. Conversely, the concepts of successive reflections and signal velocity are not as useful as the concept of the impedance plane in the analysis of test situations involving the use of steady-state sinusoidal currents.

\section{Use of Masks}

The use of metal masks to produce fields of small cross-sectional area in order to obtain surface resolution has been reported earlier. (4) It has been found possible to adapt these masks to a test system which depends upon information from the reflected fields. The system then possesses the geometrical convenience associated with the typical test system using test probes.

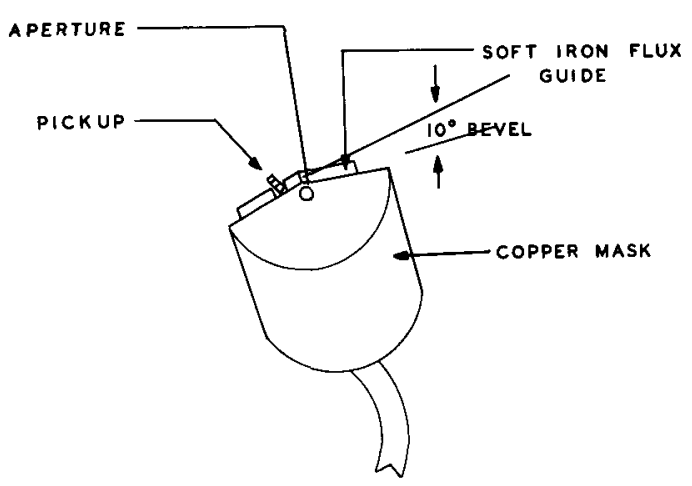

Figure 19. A Line Drawing of One Type of Mask-Aperture Assembly
A line drawing of one of the mask-aperture assemblies is shown in Figure 19. The field inside the mask is produced by a coil or possibly by a spark discharge. A localized field around the aperture exists over a path long enough in space to be useful for the purposes of nondestructive testing. It is possible to design the maskaperture assembly so that only an insignificant voltage is developed across the pickup coil when no test specimen is present near the aperture. The introduction of a good conductor over the

aperture then produces a change in the resultant fields at the location of the pickup and, consequently, a voltage across it. This voltage contains useful information about the effective resistivity and permeability of the metal in a localized area under the aperture. The metal test specimen need not pass over the pickup, but if, for example, tubing is being inspected, the tube should pass directly over the aperture. The function of the soft iron flux guide is to provide a low reluctance path for the stray fields which exist all around the aperture. Not every design of the mask-aperture assembly needs this flux guide.

D. The Signal Produced by the Mask-Aperture Assembly

Figure 20 shows a set of waveforms, plotted from photographs of oscilloscope patterns, which show curves obtained from the output of the pickup. This is a synthetic test situation intended to illustrate that although, as mentioned before, discrete echoes which can be identified in time are not available, yet it is possible to locate a segment of time which is 
particularly rich in information about conditions in the metal at a certain depth. Curve (a) in Figure 20 represents the total signal at the pickup with a 0.010-in.-thick aluminum shim over the aperture, and curve (b) with very thick aluminum over the aperture. The difference between the 2 waveforms represents the energy reflected from the back face of the 0.010-in. aluminum shim material. It may be noticed that there is no change in the peak negative value of the voltage pulse under these 2 conditions. This is the part of the pulse associated with the reflection from the surface, so only those conditions which affect the resistivity of the metal very near the surface are likely to produce much effect on this part of the waveform.

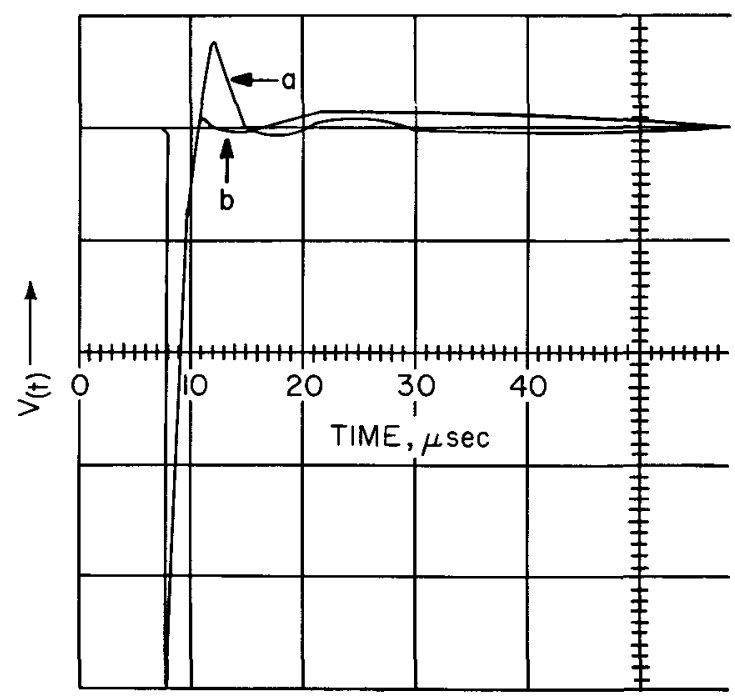

Figure 20

A Set of Waveforms Obtanned from Photographs of Oscilloscope Patterns Which Show Curves Obtained from the Output of the Plckup. Curve (a) represents the total signal at the pickup with a $0.01-1 n$.-thick aluminum shim over the aperture, curve (b) with very thick aluminum over the aperture. The difference between the two waveforms represents the energy reflected from the back face of the $0.01-i n$. aluminum shim material.

Figure 21 presents the same type of information, but this time only the amplified positive portion of the waveform is shown after it passes through a gate which is variable in width and time of occurrence during the cycle. This shows the difference in signal produced between stainless steel tubing of 0.062 -in. wall and of 0.085 -in. wall. It can be seen that it is entirely possible to select a portion of the waveform produced by the surface and interior reflections which contains a significant quantity of information about conditions at some depth in the metal, and at the same time use another part of the waveform as a measure of aperture-to-metal distance.

Figure 21

The Amplified Positive Portion of the Voltage Waveform Developed across the Pickup. Curve (a) shows the signal produced from stanless steel tubing of $0.062-1 n$. Wall and curve (b) the signal produced by tubing of $0.085-1 n$. wall, other dimensions being constant.

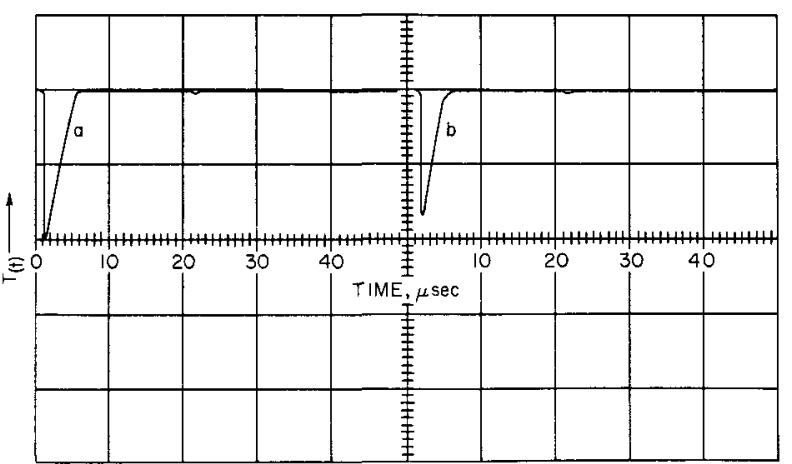


Figure 22 shows the peak value of the voltage pulse induced in the pickup, plotted as a function of the distance between the aperture and the test specimen. Metal resistivity is the variable parameter for this set of curves. Although these curves were obtained with $10-\mu$ sec pulses, pulses with durations down to below $1 \mu$ sec will produce substantially the same results, because, again, the peak values plotted in the curves are largely dependent on the surface reflection.

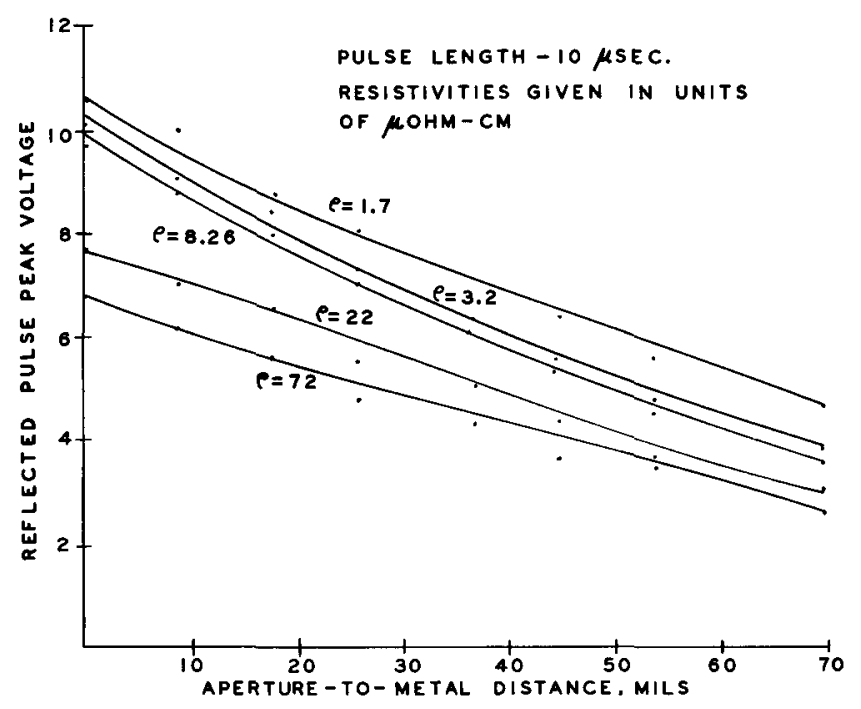

Figure 22

The Peak Value of the Voltage Pulse Induced in the Pickup, Plotted as a Function of the Distance between the Aperture and the Test Specimen. Metal Resistivity is the Variable Parameter for This Set of Curves.

No attempt will be made to present here the factors behind the design of the mask-aperture assemblies. A considerable amount of information has been acquired, but it is certain that the optimum designs for various test situations have not been developed. The type shown in the line drawing works well enough to use for a wide variety of purposes. At a time when the field in a conducting plane located under a sinusoidal current-carrying coil has not been exactly analyzed, it may be appreciated that the solutions of the boundary-value problems associated with systems like the maskaperture assemblies are of prohibitive difficulty.

\section{E. Features of the System}

Pulses of 2 different durations were used. The 2 voltage pulses induced in the pickup are shown in Figure 23 as they appear on an oscilloscope face. One pulse is of such a short duration that the information received at the pickup is in most test situations a measure of aperture-tospecimen distance. The duration of the longer pulse is chosen for its effectiveness in the test problem at hand. It is intended to deliver information about conditions inside the test specimen. In many applications, the peak positive value of the pulse of longer duration could also be used for this function since it is composed mostly of the primary surface reflection. But for reasons of flexibility this is not done, and the longpulse duration and the portion of the long-pulse waveform selected for extraction of information about the internal metal condition can be then chosen to fit the test situation. 


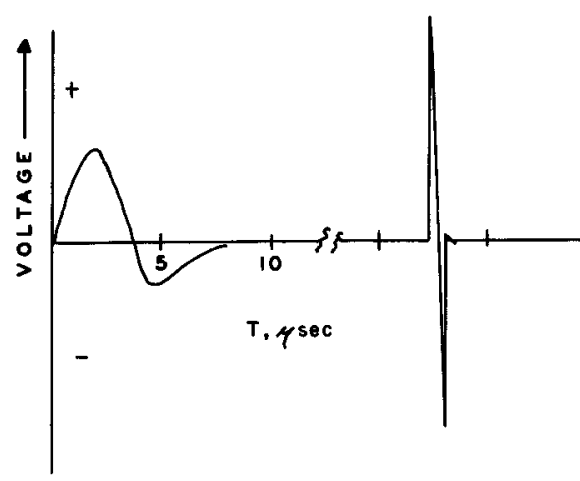

Figure 23. An Idealized Representation of the Short - and LongPulse Waveforms as They appear on an Oscilloscope Face.
A block diagram of a pulsed-field reflection system is shown in Figure 24. The current pulses which are applied to the field coil occur at different parts of the cycle, so the voltage pulses from the pickup can be amplified by common circuits. After amplification, the 2 pulses are separated by gate circuits, rectified and fed into a mixer section where effects of aperture-to-specimen distance are eliminated. The circuitry of this system from this point on is entirely conventional, with filters and sensitivity compensation being just as useful as they are in sinusoidal systems. Although the circuitry is not particularly simple in the number of elements used, it is quite easy to set up and adjust, and far fewer problems of stability are encountered as compared with sinusoidal test systems of the same capabilities.

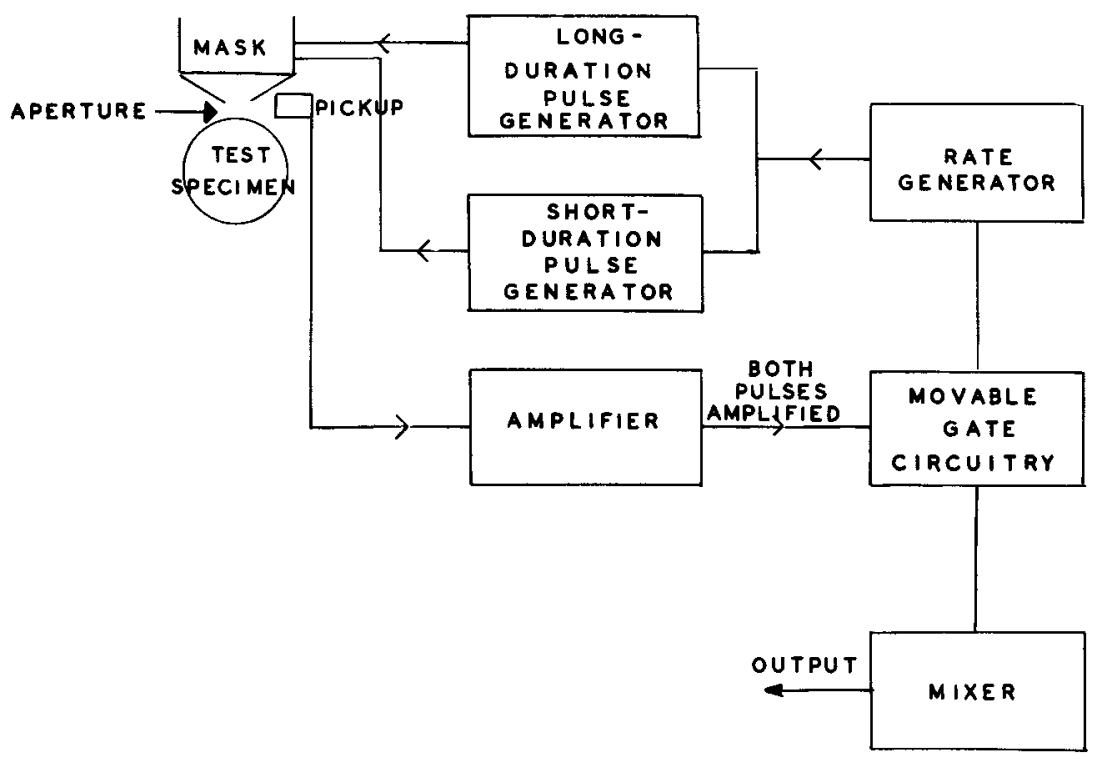

Figure 24. A Block Diagram of the Pulsed-Field Reflection System

F. Some Advantages of This Approach

One of the most critical sections of many sinusoidal test systems, the bridge, has been eliminated, along with the problems which were associated with it. Another troublesome problem in sinusoidal systems is the drift and instability encountered from the effects of ambient temperature, ageing, stray magnetic fields, and other more obscure causes on the test probes or coils. This problem has been eliminated along with the elements themselves. These effects can still occur in the elements of the maskaperture assembly, but they do not play a significant role in the magnitude of the constituents of the reflected field. Changes in pulse length, equivalent to changing frequency in sinusoidal equipment, can be made instantaneously. 
It has been found that the surface resolution obtainable with the maskaperture assemblies can be made better than can be obtained with the smallest test probes it has been found possible to construct. However, this advantage is not as important as some of the advantages previously mentioned. In some applications, for instance, in the very critical inspection of thin-wall tubing, it is necessary, but for other applications it is unnecessary or even undesirable. In any event, a highly localized field at the metal surface will always spread as it diffuses into the metal. This test system is currently being used for the testing of considerable quantities of thin-wall nonferrous tubing and the quality of the sodium bond of prototype reactor fuel elements. In these applications it has replaced sinusoidal equipment which was formerly used for this purpose.

Development work continues on this method, since many unanswered questions remain. But even at this stage of development it would seem to be a useful approach to some of the important problems in the nondestructive testing field. 